\title{
Correction to: Empirical Model of 10-130 MeV Solar Energetic Particle Spectra at 1 AU Based on Coronal Mass Ejection Speed and Direction
}

\author{
Alessandro Bruno ${ }^{1,2}$ (D) - Ian G. Richardson ${ }^{1,3}$
}

Accepted: 24 February 2021 / Published online: 8 March 2021

(C) Springer Nature B.V. 2021

\section{Correction to: Solar Phys. (2021) 296: 36 \\ https://doi.org/10.1007/s11207-021-01779-4}

This article was published with erroneous versions of two references and Figures 9, 10, 11, and 12 which have been corrected.

Publisher's Note Springer Nature remains neutral with regard to jurisdictional claims in published maps and institutional affiliations.

The original article has been corrected.

The original article can be found online at https://doi.org/10.1007/s11207-021-01779-4

A. Bruno

alessandro.bruno-1@nasa.gov

I.G. Richardson

ian.g.richardson@nasa.gov

1 Heliophysics Division, NASA Goddard Space Flight Center, Greenbelt, MD, USA

2 Department of Physics, Catholic University of America, Washington, DC, USA

3 Department of Astronomy, University of Maryland, College Park, MD, USA 